\title{
Representações sociais de professores pré-serviço de língua estrangeira sobre feedback corretivo oral ${ }^{1}$
}

\section{Pre-service foreign language teachers' social representations on oral corrective feedback}

\author{
Aline Ribeiro Pessôa* \\ *Universidade Federal do Oeste da Bahia (UFOB), Barreiras, Bahia / Brasil \\ aline.pessoa@ufob.edu.br \\ https://orcid.org/0000-0003-0766-9164 \\ Marília dos Santos Lima** \\ **Universidade do Vale do Rio dos Sinos (Unisinos), São Leopoldo, Rio Grande do Sul \\ / Brasil \\ marilialim@unisinos.br
}

https://orcid.org/0000-0003-1054-0345

\begin{abstract}
RESUMO: Este artigo discute uma investigação sobre as representações sociais (MOSCOVICI, 1978, 2003, 2007) de professores pré-serviço de inglês e espanhol sobre feedback corretivo oral. Participaram do estudo 64 estudantes concluintes de cursos de Letras das cinco diferentes regiões brasileiras. Uma vez que as representações sociais podem guiar os comportamentos, investigar as representações sociais dos participantes pode revelar como eles tendem a lidar com erros orais em suas futuras salas de aula. Os dados foram coletados por meio de um instrumento de associação livre de palavras e um grupo focal online. A análise revelou que os participantes ancoram feedback corretivo oral a um entendimento tradicional de correção do erro e aponta para a necessidade de incluir feedback corretivo oral no currículo de cursos de Letras.
\end{abstract}

PALAVRAS-CHAVE: representações sociais; feedback corretivo oral; língua estrangeira.

\footnotetext{
${ }^{1}$ Este trabalho está vinculado ao Grupo de Pesquisa $\mathrm{CNPq}$ 'A ação colaborativa e as tarefas pedagógicas no ensino e na aprendizagem de línguas estrangeiras', coordenado pela segunda autora, junto ao PPG em Linguística Aplicada da Universidade do Vale do Rio dos Sinos.
} 


\begin{abstract}
This article discusses an investigation about the social representations (MOSCOVICI, 1978, 2003, 2007) of pre-service teachers of English and Spanish on oral corrective feedback. The study population were 64 senior students of Letters programs from the five different Brazilian regions. Considering that social representations may guide behavior, researching the participants' social representations may reveal how they tend to deal with oral errors in their future teaching. Data were collected using a free word association instrument and an online focus group. The analysis showed that the participants' social representations are anchored on traditional understanding of error correction, and points to the need of including oral corrective feedback in the curriculum of Letters programs.
\end{abstract}

KEYWORDS: social representations; oral corrective feedback; foreign language.

\title{
1 Introdução
}

Os erros produzidos por aprendizes de língua estrangeira (doravante LE) são alvo de pesquisas diversas, que revelam, cada vez mais, o papel essencial desempenhado pelo feedback corretivo oral no suporte que professores precisam fornecer a seus estudantes para mediar a aprendizagem da LE (SHEEN; ELLIS, 2011; LYSTER; SAITO; SATO, 2013; BATTISTELLA; LIMA, 2015; 2017; LIMA; PESSÔA, 2016, entre outros).

Feedback corretivo oral é aqui entendido como uma reação à produção oral incorreta de um aprendiz de LE, cujo objetivo é estimular a aprendizagem da língua, levando o aprendiz a perceber sua fala incorreta e corrigi-la. A partir das informações propiciadas pelo feedback corretivo oral, os aprendizes são instigados a captar a diferença entre a forma produzida e aquela desejada.

Apesar de seu papel relevante, o feedback corretivo oral pode causar experiências negativas no aprendiz a depender do modo como seja conduzido. Por essa razão, Lima e Pessôa (2016) salientam a importância de cursos de Letras encontrarem espaços para debater o tema, propiciando formação mais completa e atualizada.

Entretanto, o simples debate não garante, necessariamente, que os futuros professores atuarão como esperado em suas salas de aula. Moscovici, psicólogo social romeno desenvolvedor da Teoria das Representações Sociais (TRS, daqui em diante), argumenta que, se quisermos compreender por que os indivíduos agem do modo como o fazem, devemos investigar 
as representações daquele grupo social, pois as representações sociais (RS, a partir de agora), coletivamente criadas e compartilhadas na vida cotidiana dos indivíduos, "formam estruturas individuais de conhecimentos e afetos que justificam, informam e orientam os membros de um grupo" (MOSCOVICI, 2003, p. 54).

A partir do entendimento de que estudantes de cursos de Letras formam um grupo social que, em suas interações diárias, criam e compartilham conhecimento, optamos por desenvolver esta pesquisa norteada pela TRS, definida como um referencial teórico que possibilita a investigação de um tipo de conhecimento que abarca explicações, crenças e ideias originadas e compartilhadas nas interações da vida cotidiana (ABRIC, 2001; JODELET, 2001; MOSCOVICI, 2003; 2007).

O estudo objetiva analisar as RS que professores pré-serviço de LE, concluintes de cursos de Letras, constroem e compartilham sobre feedback corretivo oral e, assim, investigar o conhecimento desses professores em formação. A pesquisa também objetiva explorar se e como o tema feedback corretivo oral é abordado em cursos de Letras e levantar quais obras científicas servem de aporte teórico para os professores pré-serviço refletirem sobre o tema.

Este artigo está organizado em seis seções, além das referências. Examinamos, nas segunda e terceira seções, respectivamente, a TRS e o feedback corretivo oral. Os procedimentos metodológicos adotados na investigação estão detalhados na quarta seção e, em seguida, na quinta seção, os dados são analisados e discutidos. As considerações finais concluem o artigo.

\section{A Teoria das Representações Sociais}

A TRS constitui-se em um referencial teórico sobre a produção do saber social. Saber, nesse sentido, refere-se a qualquer conhecimento socialmente construído e compartilhado (MOSCOVICI, 1978, 2003, 2007; JODELET, 2001; JOVCHELOVITCH, 2011). Essa teoria busca investigar como os indivíduos tornam-se conhecedores de uma realidade social, assim como procura compreender as representações que os grupos sociais constroem.

Abric (2001, p. 156) conceitua RS como "um conjunto organizado de opiniões, de atitudes, de crenças e de informações referentes a um objeto 
ou uma situação" que os indivíduos elaboram acerca de um objeto, de um conceito, de outras pessoas ou grupos. Jodelet (2001, p. 22) define RS como "uma forma de conhecimento socialmente elaborado e partilhado, com um objetivo prático, e que contribui para a construção de uma realidade comum a um conjunto social". Esse conhecimento "espontâneo" ou "ingênuo", também denominado como conhecimento do senso comum, é o produto da construção de saberes gerado nas interações dos membros de uma determinada comunidade.

Resumidamente, as RS formam um tipo de conhecimento que nasce nas interações cotidianas dos indivíduos em um dado grupo social. Elas funcionam como "um sistema de interpretação da realidade [que] guia os comportamentos e as práticas" dos indivíduos, permitindo-lhes "explicar e justificar suas condutas em uma situação” (ABRIC, 1998, p. 27-30). Desse modo, o estudo das representações de um grupo social sobre determinadas questões possibilita acessar o que os indivíduos pensam sobre aquelas questões.

As RS ligam um sujeito a um objeto (JODELET, 2001; JOVCHELOVITCH, 2011), pois são a representação de algo (o objeto da representação) por alguém (o grupo social). Qualquer objeto - seja uma pessoa, coisa, fenômeno da natureza ou ideia, tanto no plano real quanto no imaginário - pode se transformar em objeto de representação social. Entretanto, para que as RS sejam construídas por um grupo, é necessário que o objeto possua suficiente "relevância cultural" ou "espessura social" (SÁ, 1998, p. 45). Em outras palavras, quando o objeto causa tensão e provoca ação.

A tensão é causada principalmente pelo desconhecimento, pois o desconhecido intriga os indivíduos e evoca temor levando-os a construírem representações para tornar o objeto menos ameaçador. A finalidade, portanto, das RS é tornar familiar algo desconhecido, não-familiar (MOSCOVICI, 1978, 2003, 2007; JODELET, 2001). Essa familiarização ocorre por meio de dois processos mentais denominados ancoragem e objetivação. Esses processos ajudam o indivíduo a entender um objeto com mais facilidade: torna-o mais familiar e, por conseguinte, mais fácil de ser entendido.

A ancoragem consiste na classificação e denominação de um objeto estranho, pois coisas não classificadas, que não possuem nome, são estranhas e, portanto, ameaçadoras (MOSCOVICI, 2007). Importante compreender 
que classificar algo implica confiná-lo a um conjunto de comportamentos e regras. Assim, quando alguém classifica uma pessoa como neurótica, ele está avaliando-a e rotulando-a. E, neste ato, é revelada sua teoria da sociedade e da natureza humana (MOSCOVICI, 2007).

Desse modo, quando nomeamos um objeto como sendo "isso" ou "aquilo" representamos a realidade, ancoramos o desconhecido em algum sentido conhecido. Então, podemos, por exemplo, relacionar o objeto de representação a um evento ou sentimento conhecido, como "a angústia dos adolescentes" ou "o cheirinho de um bebê".

Conforme Moscovici (2003), o processo mental denominado objetivação busca transformar algo abstrato em algo quase concreto, tornando visível o invisível. Um exemplo clássico é a associação entre a teoria da relatividade e a imagem de Einstein.

Moscovici (2003, p. 61) sustenta que a ancoragem e a objetivação

transformam o não-familiar em familiar, primeiramente transferindo-o a nossa própria esfera particular, onde nós somos capazes de comparálo e interpretá-lo [ancoragem]; e depois, reproduzindo-o entre as coisas que podemos ver e tocar e, consequentemente, controlar [objetivação].

Nesta investigação, elegemos feedback corretivo oral na aula de LE como objeto de representação, pois entendemos que, na dinâmica da sala de aula de LE, as correções possuem suficiente espessura social. Adotamos, como grupo social investigado, os estudantes concluintes de cursos de licenciatura em Letras, pois interessa-nos conhecer o que esse grupo social pensa sobre o assunto, a que esse grupo compara a correção, e, desse modo, inventariar as "âncoras" que sustentam esse conhecimento. Ao investigarmos as ancoragens dos estudantes, professores pré-serviço, sobre feedback corretivo oral, estamos pesquisando aquilo que pode vir a guiar as condutas desses futuros professores.

\section{Feedback corretivo oral}

O papel dos erros produzidos pelos aprendizes de LE e, consequentemente, a maneira como os professores devem lidar com esses erros, têm uma longa e controversa história, variando conforme as distintas concepções de ensino-aprendizagem de LE em voga (FIGUEIREDO, 2002; RUSSELL, 2009). 
O método audiolingual, predominante no Brasil desde a década de 1950 até o início dos anos de 1980, concebia que o ensino de LE deveria promover a acurácia. De acordo com essa perspectiva metodológica, a aprendizagem de LE ocorria pela internalização de novos hábitos. Os erros produzidos pelos aprendizes eram percebidos como respostas inadequadas a um dado estímulo e demonstravam falta de aprendizagem. Cabia ao professor, como único detentor do conhecimento, a tarefa de prover correções imediatas para extinguir os erros porque "quem errava acabava aprendendo os próprios erros" (LEFFA, 1988, p. 221).

As teorias de ensino-aprendizagem subjacentes à abordagem comunicativa, paulatinamente introduzida no Brasil a partir de 1978 (ALMEIDA FILHO, 2001), modificaram o foco de atenção da acurácia para a comunicação. A nova perspectiva metodológica enfatiza que os professores devem oportunizar o engajamento dos aprendizes em atividades variadas que promovam interação, comunicação e uso da LE de modo significativo. O erro que o aprendiz verbaliza nessas interações passou a ser caracterizado como a tentativa do aprendiz em se comunicar ou um meio para testar suas hipóteses sobre a língua que está aprendendo. Desse modo, como argumentam Battistella e Lima (2010), a informação disponibilizada pelo feedback propicia aos aprendizes reflexões sobre a língua que confirmem, refutem, modifiquem e reformulem suas hipóteses. Para tanto, é necessário que o feedback seja percebido e compreendido pelo aprendiz.

Apesar de seu papel relevante para a aprendizagem, como demonstrado pela literatura atual (LYSTER; SAITO; SATO, 2013; LIMA; PESSÔA, 2016; BATTISTELLA; LIMA, 2017), há professores que relutam em prover feedback corretivo oral ou fornecem-no tão sutilmente que o aprendiz não consegue percebê-lo como tal. Assim agindo, esses professores reduzem as oportunidades de aprendizagem, pois o aprendiz pode, por exemplo, interpretar o não recebimento de feedback corretivo como a confirmação de sua hipótese.

A complexa tarefa de fornecer feedback corretivo oral requer que os professores atentem às necessidades específicas de cada aprendiz e considerem o tipo de atividade conduzida no momento da interação. Além disso, dada a estreita relação, destacada por Swain (2011), entre emoção e cognição no processo de aprendizagem de uma LE, é essencial que os professores ponderem acerca dos fatores afetivos, especialmente a respeito do nível de ansiedade que o feedback possa provocar. 
Ao considerarem o tipo de atividade, o momento da interação e questões emocionais, os professores podem lançar mão de diversos tipos de feedback corretivo oral. ${ }^{2}$ Lyster, Saito e Sato (2013) argumentam que as diversas investigações conduzidas confirmam a relevância do fornecimento de feedback corretivo e não identificaram a existência de algum tipo específico de feedback como o mais eficaz para a aprendizagem.

Nos últimos anos, o termo feedback corretivo oral passou a ser empregado em substituição à expressão correção do erro. Os pesquisadores (ELLIS, 2009; LYSTER; SAITO, 2010; LYSTER; SAITO; SATO, 2013; LIMA; PESSÔA, 2016; BATTISTELLA; LIMA, 2015, 2017, entre outros) parecem considerar o uso da expressão feedback corretivo como mais aceitável na medida em que feedback se refere a distintas formas de fornecer ao aprendiz tanto comentários positivos sobre a compreensão de suas elocuções quanto indicações de imperfeições no uso da LE. Cabe esclarecer que adotamos, para a coleta de dados, o termo correção do erro oral porque essa é a terminologia mais amplamente usada por professores e estudantes. Empregar outra terminologia poderia requerer explicações a respeito do termo e isso levaria os participantes a agir com menor espontaneidade. Assim sendo, ao longo das próximas seções, nas quais expomos a metodologia desenvolvida, a análise e a discussão dos dados, usaremos o termo correção do erro oral.

\section{Procedimentos metodológicos}

A TRS não privilegia instrumentos específicos para coleta de dados, pois, como ressaltado por Sá (1998), o aspecto mais importante na investigação das RS não é o instrumento adotado, mas a garantia da espontaneidade do discurso produzido pelos participantes.

Nesse sentido, Abric $(1998,2001)$ recomenda o uso da técnica de evocação livre de palavras, também denominada associação livre de palavras, pois considera que o instrumento garante espontaneidade nas respostas dos participantes e permite ao pesquisador acessar mais facilmente os elementos constituintes do conteúdo de uma representação social. Almeida (2005), por sua vez, sugere a combinação de distintos instrumentos para permitir ao investigador acessar as RS a partir de diferentes perspectivas. Nesta

\footnotetext{
${ }^{2}$ Sobre discussões detalhadas e ilustradas de tipos de feedback corretivo oral, ver Battistella e Lima (2015) e também Lima e Pessôa (2016).
} 
investigação, coletamos os dados por meio de um instrumento de associação livre de palavras combinado à realização de um grupo focal.

A técnica de evocação de palavras solicita que, a partir de um estímulo verbal indutor, o indivíduo associe outras palavras que lhe venham imediatamente à lembrança, hierarquize-as em ordem decrescente de importância e, finalmente, justifique a palavra escolhida como a mais importante. $\mathrm{O}$ instrumento de associação livre de palavras usado neste estudo (APÊNDICE A) solicitou aos respondentes que (1) evocassem as quatro primeiras palavras que imediatamente viessem à memória assim que lessem a expressão indutora Correção do erro oral na aula de língua estrangeira é ..., (2) indicassem qual das quatro palavras evocadas era a mais importante, e (3) justificassem o porquê daquela ser a palavra mais importante. Desse modo, obtivemos um corpus de vocábulos que nos forneceu o conteúdo da representação daquele grupo social.

Grupo focal caracteriza-se como uma técnica de entrevista para coletar dados por meio de debates fortemente pautada na interação entre os participantes (GATTI, 2005; GASKELL, 2012). Optamos pela utilização de grupo focal em ambiente virtual (DUARTE, 2007; REZABEK, 2000) para possibilitar a participação de respondentes geograficamente distantes uns dos outros. Inspiradas pelo trabalho de Severo (2016), adotamos o aplicativo WhatsApp como meio de interação. O uso da técnica do grupo focal objetivou (1) aprofundar nossa compreensão acerca dos sentidos atribuídos ao termo indutor 'correção do erro oral', (2) investigar se e como o tema, correção do erro oral, é abordado em cursos de Letras e (3) levantar quais publicações científicas servem de aporte teórico para nortear os debates sobre o tema.

Os critérios para a inclusão dos participantes desta pesquisa estabeleciam que estes deveriam (1) ser estudantes concluintes, matriculados em um dos dois últimos semestres de cursos de licenciatura em Letras com habilitação em ensino de língua inglesa ou espanhola, (2) ser alunos dos professores contatados pelas pesquisadoras e em cujas turmas o instrumento de associação livre de palavras seria aplicado, (3) aceitar participar da investigação e (4) estar presentes na aula em que a pesquisadora aplicaria o instrumento de associação livre de palavras.

Um total de 64 professores pré-serviço das cinco regiões administrativas do Brasil participaram deste estudo respondendo ao instrumento de associação livre de palavras. O Quadro 1, a seguir, sintetiza a distribuição dos participantes em seus respectivos cursos. 
QUADRO 1 - Distribuição dos participantes

\begin{tabular}{|c|c|c|c|}
\hline $\begin{array}{c}\text { Licenciatura em } \\
\text { língua }\end{array}$ & Categoria administrativa da IES & IES localizada na região & Quantidade \\
\hline Espanhola & Pública & Norte & 11 \\
\hline Inglesa & Pública & Nordeste & 15 \\
\hline Inglesa & Privada & Centro-Oeste & 14 \\
\hline Espanhola & Privada & Sudeste & 9 \\
\hline Inglesa & Privada & Sul & 15 \\
\hline
\end{tabular}

Fonte: Elaborado pelas autoras

Do total de participantes, 14 já atuavam como docentes de LE: 12 em cursos livres e dois em escola de educação básica e em cursos livres. A idade dos participantes variava de 19 a 39 anos. Quanto à trajetória de aprendizagem da LE, constatamos que quarenta participantes estudaram a LE em cursos livres antes de iniciarem o curso de Letras. O perfil do grupo social investigado neste estudo pode ser mais facilmente observado no Quadro 2, a seguir.

QUADRO 2 - Perfil dos participantes distribuídos por região geográfica

\begin{tabular}{|c|c|c|c|c|c|c|}
\hline & & $\begin{array}{l}\text { Região } \\
\text { Norte }\end{array}$ & $\begin{array}{c}\text { Região } \\
\text { Nordeste }\end{array}$ & $\begin{array}{c}\text { Região } \\
\text { Centro- Oeste }\end{array}$ & $\begin{array}{l}\text { Região } \\
\text { Sudeste }\end{array}$ & $\begin{array}{c}\text { Região } \\
\text { Sul }\end{array}$ \\
\hline \multirow{2}{*}{ Faixa etária } & 19 a 29 & 10 & 7 & 10 & 4 & 11 \\
\hline & 30 a 39 & 1 & 8 & 4 & 5 & 4 \\
\hline \multirow{2}{*}{ Gênero } & $\mathbf{F}$ & 6 & 12 & 7 & 7 & 12 \\
\hline & $\mathbf{M}$ & 5 & 3 & 7 & 2 & 3 \\
\hline \multirow{3}{*}{$\begin{array}{l}\text { Estudo de LE } \\
\text { anterior ao curso } \\
\text { de Letras }\end{array}$} & $\begin{array}{l}\text { Sim, } 2 \text { a } 6 \\
\text { semestres }\end{array}$ & 2 & 2 & 3 & 3 & 5 \\
\hline & $\begin{array}{l}\text { Sim, } 7 \text { a } 14 \\
\text { semestres }\end{array}$ & 6 & 3 & 7 & 6 & 3 \\
\hline & Não & 3 & 10 & 4 & - & 7 \\
\hline \multirow{2}{*}{ Leciona LE } & Sim & 2 & 1 & 3 & 4 & 4 \\
\hline & Não & 9 & 14 & 11 & 5 & 11 \\
\hline
\end{tabular}

Fonte: Elaborado pelas autoras 
Todos os participantes que demonstraram disponibilidade e interesse para continuar a participar da pesquisa foram convidados a integrar o grupo focal em ambiente virtual. Participaram do grupo focal nove estudantes de cursos localizados nas cinco regiões do país, com idade entre 23 e 30 anos. Destes participantes, dois são do gênero masculino e sete do feminino, sendo que três já atuam como professores de LE. O grupo focal se encontrou virtualmente duas vezes em datas e horários previamente acordados.

Ao longo da próxima seção, na qual analisamos e discutimos os dados da investigação, usamos Estudante 1 a Estudante 64 para nos referirmos aos 64 participantes respondentes do instrumento de associação livre de palavras. Os nove participantes do grupo focal são identificados por codinomes.

\section{Representações sociais de estudantes concluintes de Letras: análise dos dados}

Os dados desta investigação foram analisados inicialmente em um procedimento quantitativo por meio de análise estatística de contagem das palavras evocadas no instrumento de associação livre de palavras. Em seguida, construímos a lista daquelas palavras identificadas como as mais importantes para representar correção do erro oral e, novamente por meio de análise quantitativa, criamos o rol de vocábulos repetidos, com frequência maior ou igual a 3 ( $\mathrm{f} \geq 3$ ), que constitui a representação social de correção do erro oral do grupo investigado. A seguir, a justificativa apresentada por cada participante acerca da palavra que havia considerado como a mais importante foi analisada qualitativamente, usando-se princípios da Análise de Conteúdo (BARDIN, 1977; MORAES, 1999), processo que permite ao pesquisador "a descoberta do que está por trás dos conteúdos manifestos" (GOMES, 2002, p. 74) e que possibilita a compreensão da realidade por meio da interpretação, captando-se tanto o conteúdo explícito quanto o implícito.

Ao todo foram evocados 256 vocábulos a partir da expressão indutora Correção do erro oral é ... Desse total, doze termos foram descartados, pois sete estavam ilegíveis e cinco em desacordo com as instruções, pois consistiam em expressões ou frases. Assim sendo, 56 palavras diferentes, obtidas a partir do total de 244 palavras evocadas, constituem o corpus inicial dos dados desta pesquisa. 
A análise estatística dos dados demonstrou que as palavras evocadas com frequência maior ou igual a 3 ( $\mathrm{f} \geq 3$ ) foram: 'necessário' ( $\mathrm{f}=48$ ), 'constrangedor' ( $f=42)$, 'importante' ( $f=22)$, 'ajuda' $(f=14)$, 'essencial' ( $\mathrm{f}=14)$, 'complicado' $(\mathrm{f}=14)$, 'desafio' $(\mathrm{f}=13)$, 'complexo' $(\mathrm{f}=9)$, 'ensino' $(\mathrm{f}=5)$, 'fundamental' ( $\mathrm{f}=4$ ), 'difícil' ( $\mathrm{f}=3$ ) e 'indispensável' ( $\mathrm{f}=3$ ).

Além de evocar as palavras, conforme exposto anteriormente, o participante deveria indicar aquela que considerasse como a mais importante. As palavras identificadas pelos participantes como a mais importante ( $\mathrm{f}$ 23) para representar correção do erro oral foram: 'necessário' ( $\mathrm{f}=20)$, 'importante' ( $\mathrm{f}=16$ ), 'essencial' ( $\mathrm{f}=8$ ), 'desafio' ( $\mathrm{f}=7$ ), 'complicado' $(\mathrm{f}=5$ ) e 'complexo' ( $f=3$ ). Esses são os vocábulos, portanto, que constituem a representação social de correção do erro oral dos participantes do estudo.

'Necessário' ( $\mathrm{f}=20)$, 'importante' $(\mathrm{f}=16)$ e 'essencial' $(\mathrm{f}=8)$ reiteradamente surgiram como as mais importantes para representar correção do erro oral, como exemplificado pelas afirmações a seguir transcritas:

Sem dúvida 'necessário' é a palavra mais importante, pois o erro, uma vez ignorado, levará o aluno ao vício do erro. Sem correção imediata ficará difícil prosseguir na aprendizagem. $\mathrm{O}$ ato de corrigir, dentro de apropriadas proporções, e com o cuidado de não constranger o aluno é essencial; ele aprende com o próprio erro. Corrigir também é ensinar. (Estudante 7)

'Importante' sem dúvida alguma é a palavra escolhida. Correção do erro oral é 'importante' porque assim o aluno não erra mais. (Estudante 15)

'Essencial' devido ao fato de ser o meio pelo qual o aprendiz pode ajustar detalhes que estão errados; faz parte do processo de ensino. Ou seja, o professor dá continuidade a seu ensino quando corrige o aluno. E o aluno amplia a aprendizagem quando é corrigido. (Estudante 26)

Os termos 'necessário' e 'importante' também emergiram durante as discussões conduzidas pelo grupo focal, como mostra o excerto transcrito a seguir.

'Importante', claro, bastante mesmo porque é natural errar quando estamos aprendendo qualquer coisa. Então é 'importante' sim que o professor intervenha nesse erro para que a gente possa aprender e parar de errar. (Patrícia) 
Concordo com tudo. A correção é muito, muito 'importante'. Como o aluno vai saber que errou se o professor não corrigir? (Eduardo)

Sim, é 'necessário' mesmo para o aluno aprender mais. Eu aprendo também quando o professor corrige os outros. Acho que todos os alunos aprendem mais e o que foi falado antes eu concordo totalmente - é 'importante' o professor corrigir e intervir para o aluno parar de errar. (Manuela)

A alta frequência das palavras 'necessário', 'importante' e 'essencial' poderia sugerir que os participantes do estudo interpretam a correção do erro oral como tendo papel relevante no processo de ensino e aprendizagem. Entretanto, o sentido que os participantes atribuem à importância da correção parece estar fortemente associado à concepção de que erros nas produções orais são reflexos de falhas de aprendizagem e a correção serviria para a superação dessas falhas. Nas palavras dos participantes, correção do erro oral é 'importante':

Para impedir o aluno que errou a enraizar o erro. (Estudante 24)

Porque se o professor não me corrigir ficarei insistindo sempre no mesmo erro. (Estudante 46)

Pois o professor deve corrigir erros que sejam provenientes de mistura da língua materna com a língua estrangeira. Não podemos permitir que, por causa de algum mal entendido, o aluno venha a assimilar a pronúncia de maneira errada. (Estudante 52)

As falas dos estudantes sugerem que eles entendem a correção como uma ação que leva o aluno a parar de errar, exatamente como pregam os métodos de ensino de LE apoiados na perspectiva behaviorista.

'Desafio' ( $\mathrm{f}=7$ ) foi o quarto vocábulo evocado como o mais importante para representar correção do erro oral. A representação é assim explicada pelos participantes:

'Desafio', claro, porque o professor deve mostrar a forma certa para o aluno, mas ao mesmo tempo o professor não pode constranger o aluno mostrando que ele errou e isso é um 'desafio' para o professor. (Estudante 3) 
É 'desafio' pois apesar de essencial para a aprendizagem, ao mesmo tempo pode travar o processo do aluno; a correção do professor pode envergonhar ou inibir o aluno. Então é 'desafio' para o professor provocar aprendizagem sem envergonhar o aluno. (Estudante 48)

'Desafio' é a primeira que vem na minha cabeça e é a mais importante exatamente porque se errou é porque não sabe e se for corrigido pode ficar inibido. (Estudante 59)

Os argumentos utilizados para justificar a importância da palavra ‘desafio' sugerem uma representação social de correção do erro oral que reconhece a relevância da ação corretiva para o processo de aprendizagem ao mesmo tempo em que apresentam a preocupação acerca de emoções desagradáveis com as quais o professor precisa saber lidar para não "constranger", "envergonhar" ou "inibir" o aluno.

A respeito desse tipo de emoção, um participante do grupo focal, Vitor, afirmou: "odeio qdo ${ }^{3}$ sou corrigido". Os comentários enviados por outros participantes usam o vocábulo 'desafio' aliando-o aos sentimentos de inibição e constrangimento que a correção pode causar, como demonstram as seguintes transcrições:

Eu também não gosto, mas sei que é útil porque aprendo. O detalhe é que é um 'desafio' corrigir e não inibir. (Jandira)

Sim... 'desafio', a depender de como seja feita a gente fica assim ... assim... constrangido. Mas também deve ser bem difícil pros profs pq eles precisam corrigir, mas fico pensando ... será q eles também ñ acham difícil? Ninguém quer constranger aluno. (Marcia)

Naquele momento do Encontro 2, duas participantes do grupo focal que exercem a docência de LE, Ana e Débora, responderam aos colegas. A interação pode ser um indício de que ‘desafio’ é associado à preocupação das estudantes-professoras em não provocar sentimentos de constrangimento ou inibição. As participantes explicaram que:

\footnotetext{
${ }^{3}$ Os enunciados dos participantes, em suas interações no WhatsApp, foram aqui transcritos exatamente como originalmente redigidos.
} 
a correção no papel, a correção de textos é fácil pq tá ali. Só eu e meu aluno vamos ver. Mas a correção oral é bem difícil mesmo. É um enorme 'desafio'. E o q acho pior é q os alunos precisam saber os erros que estão cometendo, mas não sei... fico sempre muito preocupada de transformar a correção em constrangimento. (Débora)

Concordo com a colega. Desafio' porq vc tem que fazer ele saber que errou porque não pode ficar errando e ao mesmo tempo interromper é chato. Mesmo qdo não interrompo, qdo falo depois, fico sempre com medo de que o aluno fique sem graça porq se ficar triste ou sem graça não vai mais participar da aula. (Ana)

A quinta e sexta palavras mais frequentemente evocadas como a mais importante para representar correção do erro oral foram 'complicado' $(\mathrm{f}=5)$ e 'complexo' $(\mathrm{f}=3)$. Os participantes justificam essas representações relacionando-as fortemente aos cuidados para os quais os professores devem atentar a fim de não provocar situações embaraçosas em sala de aula.

Os participantes afirmam que o processo de correção do erro oral é:

'Complexo' porque dependendo da situação você pode acabar assustando o aluno e o desestimulando a aprender a língua. (Estudante 5)

'Complexo' devido a maneira em que se dá a correção o professor pode constranger ou fazer com que haja retrocesso na aprendizagem. (Estudante 12)

'Complicado' porque nem sempre a correção vai ser vista como uma ajuda que o professor quer dar para o aluno. Dependendo da forma como o professor corrige, o aluno pode interpretar de forma errada e se ofender. (Estudante 29)

'Complicado' porque o professor quer mostrar o jeito certo, mas não pode ofender o aluno. (Estudante 64)

Parece-nos correto afirmar que os participantes ancoram correção do erro oral a 'complexo' e 'complicado', assim como a 'desafio' anteriormente discutido, relacionando aquelas palavras a questões emocionais. Nenhum dos participantes justifica a correção do erro oral como complexa ou complicada em termos cognitivos.

Salientamos que catorze dos participantes do estudo atuam como professores de LE e precisam, em suas aulas, decidir se devem fornecer feedback corretivo, como e quando fazê-lo, sem possuírem qualquer arcabouço 
teórico para tal. Essa talvez seja a razão para que esses participantes representem socialmente correção do erro oral como 'desafio', 'complicado' ou 'complexo'.

Cabe destacar que o vocábulo 'constrangedor', apesar de altamente frequente nas evocações ( $\mathrm{f}=42$ ), foi hierarquizado como o mais importante para representar correção do erro oral por um único participante. Assim sendo, essa ancoragem não pode ser entendida como representação social do grupo estudado, e, consequentemente, não foi analisada.

A fim de investigar se e como feedback corretivo oral é abordado em cursos de Letras, bem como levantar quais obras científicas servem de aporte teórico para as discussões desenvolvidas em sala de aula, foi solicitado aos participantes do grupo focal que debatessem sobre como estavam se preparando para lidar com correção de erros escritos e orais em suas futuras práticas e apontassem quais textos tinham sido usados em seus cursos como provocadores de discussões. A interação iniciou com um participante afirmando que:

Estudamos sobre tanta coisa, mas eu nunca aprendi como fazer correção do erro oral, também nunca estudei sobre como corrigir redações. No meu curso, pelo menos, nunca estudamos nada sobre como corrigir. (Eduardo)

Os participantes respondem a Eduardo com comentários sobre os tópicos estudados, que incluem "erros" e "enganos" (Bianca, Eduardo, Jandira, Manuela, Marcia, Patrícia e Vitor), "fossilização" (Bianca, Débora, Eduardo, Manuela, Jandira e Patrícia), “teoria de Selinker” (Bianca, Eduardo e Vitor), "hipóteses de Krashen” (Bianca, Eduardo, Manuela, Marcia e Vitor), "interlinguagem” (Marcia) e "interlíngua" (Débora, Manuela, Eduardo e Vitor). Nas palavras dos participantes:

Estudei fossilização e interlíngua no texto aqui... é... A hipótese da gramática universal e a aquisição de segunda língua escrito por Andréa Machado de Almeida Mattos. Não sei o nome do livro. Está escrito assim: Rev. Est. ling., Belo Horizonte, v.9, n.2, p.51-71, jul./dez. 2000. Mas não fala nada de correção. (Débora)

Usei o livro de Celce-Murcia, o Teaching English as a second or foreign language. Não tenho certeza, mas sei que estudei as hipóteses de Krashen, erros, enganos, interlinguagem, só não tenho certeza se foi nesse livro daqui, mas sei que não vi nada de como corrigir não. (Marcia) 
Eu também não vi nada. Lembro de ter estudado erros e enganos, fossilização, a teoria de Selinker e hipóteses de Krashen, acho que foi no livro chamado Lingüística aplicada a la enseñanza del español como lengua extranjera. Acho que não sou muito organizada. (Bianca)

$\mathrm{Na}$ disciplina que lemos erros e enganos, [...] não usamos um livro só. A profa manda muitos artigos, não sei agora exatamente em qual artigo li, mas aprendi sobre erros e enganos, fossilização, tudo aí que disseram, até fiz prova que caiu isso; mas eu também não estudei como fazer a correção. (Jandira)

Olha, eu sei o que estudei mas não sei os textos. Posso garantir que estudei a interferência da língua materna, a interlíngua, erros globais e locais, enganos, fossilização. Adorei aprender isso. Gosto muito de Krashen que estudei as hipóteses também. Não li nada de corrigir. Não teve aula disso. (Manuela)

Lembro de fossilização, a interferência da língua materna, interlíngua, erros, enganos e de Krashen e Selinker, mas não faço mais ideia se foi apostila da professora ou slide. Só que repito o que disse antes. Não estudei nada de correção. (Eduardo)

Eu também não. Alguém aqui estudou? (Ana)

Dois participantes, Patrícia e Vitor, estudaram a mesma obra de Leffa (1988), como ilustrado por suas falas transcritas a seguir:

Estudei um texto que fala de erros, mas não estudei nada sobre correção... deixa ver o nome aqui: Metodologia do ensino de línguas [a pesquisadora solicitou a referência bibliográfica do texto]. A referência é LEFFA, Vilson J. Metodologia do ensino de línguas. In BOHN, H. I.; VANDRESEN, P. Tópicos em linguística aplicada: $\mathrm{O}$ ensino de línguas estrangeiras. Florianópolis: Ed. da UFSC, 1988. p. 211-236. Mas neste texto aqui não tem nada sobre como corrigir. (Patrícia)

Também li este texto. Foi bem discutido na sala de aula, mas é verdade que ali não fala de corrigir não. Eu sei que estudei Selinker, Krashen, interlíngua e coisa e tal mas corrigir texto oral ou escrito não. (Vitor)

Os dados coletados nos encontros do grupo focal evidenciam que os participantes não se recordam de qualquer leitura ou debate desenvolvido sobre como fazer correção de erros orais ou escritos. Há, assim, indícios de que o tema não é objeto de estudo em cursos de licenciatura em Letras, como o trabalho de Lima e Pessôa (2016) sugere. 
A constante referência aos estudos acerca de erros e enganos, fossilização e noção de interlíngua leva-nos a considerar a possibilidade desse conhecimento ter favorecido os participantes desta pesquisa a representarem socialmente correção do erro oral como importante no sentido de prevenção à fossilização, pois eles explicam que "a correção é de primordial importância para que o aluno não continue errando e internalize esse erro" (Estudante 20); "a correção instiga o aprendiz a falar corretamente" (Estudante 34) e, ainda, que "a correção do erro oral na aula de LE é importante, pois o erro, uma vez ignorado, levará o aluno ao vício do erro” (Estudante 7).

As interações dos participantes do grupo focal indicam que aspectos atualizados acerca de feedback corretivo oral são desconhecidos, assim como a própria terminologia. Os diversos depoimentos dos participantes, tanto nas justificativas dos vocábulos mais importantes quanto nas interações nos encontros do grupo focal, evidenciam entendimentos tradicionais sobre o conceito de erro e sua correção. O erro é definido como "algo intolerável especialmente no nível avançado" (Estudante 44) ou "prova que o aluno não aprendeu" (Estudante 57), e a correção como "tem que consertar para o aluno aprender" (Estudante 10) ou "mostrar na hora o jeito certo" (Estudante 31).

\section{Considerações finais}

A TRS é usada para investigar o conhecimento de um determinado grupo social acerca de um objeto em particular. Neste estudo, esse é o aporte teórico utilizado para investigar o conhecimento de 64 estudantes, concluintes de cursos de licenciatura em Letras com habilitação em ensino de língua inglesa ou língua espanhola das cinco regiões administrativas do Brasil, sobre feedback corretivo oral na aula de LE.

O estudo objetivou não apenas desvendar os sentidos atribuídos pelos estudantes ao objeto - feedback corretivo oral -, como também explorar se e como esse tema é tratado em cursos de Letras. Com a finalidade de atingir o objetivo proposto, coletamos os dados por meio de um instrumento de associação livre de palavras e, em seguida, pela realização de um grupo focal em ambiente virtual.

A análise dos dados revela que os participantes ancoram feedback corretivo oral a 'necessário', 'importante' e 'essencial', limitado a uma concepção tradicional de erro e correção. Os participantes não demonstram 
conceber erros como possíveis hipóteses formuladas sobre a língua. Eles consideram que o erro do aprendiz precisa ser corrigido "para impedir o aluno que errou a enraizar o erro" (Estudante 24). É, nesse sentido, fortemente aliado a noções dos conceitos de interlíngua e fossilização, que os participantes representam feedback corretivo oral como 'importante', pois o professor deve "intervir para o aluno parar de errar" (Manuela). Há indícios de falta de compreensão de fornecimento de feedback corretivo com critérios que ampliem o conhecimento do aprendiz, aproveitando o que ele já sabe da/sobre a língua que está aprendendo.

Os participantes também ancoram feedback corretivo oral a 'desafio', ‘complexo' e ‘complicado’ comparando-o às emoções desagradáveis provocadas, tais como constrangimento e inibição.

Uma vez que o conteúdo representacional sobre feedback corretivo compartilhado pelos participantes, professores pré-serviço de LE, formam um tipo de conhecimento que possivelmente servirá como guia de suas condutas, os resultados desta investigação podem antever como esses futuros professores atuarão em sala de aula. Nesse sentido, a preocupação suscitada pelos resultados deste estudo é que, por um lado, os professores tenderão a agir de modo a extinguir o "vício do erro", e, por outro, a intensa preocupação em não causar sentimentos negativos no aprendiz pode leválos a evitar o fornecimento de feedback corretivo, apesar de reconheceremno como 'importante' ou 'necessário'. Outra possibilidade para não provocar constrangimento é o professor fornecer feedback corretivo tão sutilmente que não seja percebido pelo aprendiz como tal.

Se uma dessas situações ocorrer, o professor não oferecerá a seus aprendizes oportunidades para percepção, reflexão e autocorreção de seus próprios erros, entendidos como os reflexos das hipóteses sobre a LE que estão aprendendo. Assim sendo, o professor não criará meios para que o fornecimento de feedback corretivo possa mediar a construção de novos conhecimentos da LE.

Quanto às informações teóricas veiculadas nos cursos de Letras acerca de feedback corretivo oral, há evidências deste não ser objeto de estudo. Como os resultados desta investigação demonstram, é fundamental que o tema seja mais discutido em cursos de formação pré-serviço. Sobre esse assunto, para que mudanças efetivas possam ocorrer na formação de futuros professores de LE, estudos como este podem ser úteis para iluminar o trabalho de professores de cursos de Letras, levando-os a investigar como 
o feedback corretivo oral é compreendido por seus discentes, quais sentidos são socialmente construídos e compartilhados e, a partir das dificuldades e angústias mencionadas, criar oportunidades para melhor compreensão acerca do tema.

Estudos aprofundados e discussões atualizadas sobre feedback corretivo oral poderão propiciar aos professores pré-serviço conhecimentos científicos sobre os diversos tipos de feedback corretivo que podem ser aliados às diferentes atividades nos distintos momentos de interação da aula de LE. Assim, os professores em formação terão subsídios teóricos que lhes permitam ancorar o feedback corretivo oral a 'necessário' ou a 'desafio' em uma perspectiva que o caracterize como um suporte que os professores precisam fornecer aos aprendizes, mediando a aprendizagem e garantindo que a estreita relação entre emoção e cognição seja considerada.

\section{Contribuição das autoras}

Os dados desta pesquisa, coletados pela primeira autora e tabulados pela segunda, foram analisados pelas duas pesquisadoras, que também redigiram e revisaram o artigo submetido.

\section{Referências}

ABRIC, J. C. A abordagem estrutural das Representações Sociais. In: MOREIRA, A. S. P.; OLIVEIRA, D. C. de. (Org.). Estudos interdisciplinares de representação social. Goiânia: AB Editora, 1998. p. 27-38.

ABRIC, J. C. O estudo experimental das representações sociais. In: JODELET, D. (Org.). As representações sociais. Rio de Janeiro: EdUERJ, 2001. p. 155-172.

ALMEIDA, A. M. O. A pesquisa em representações sociais: proposições teóricometodológicas. In: SANTOS, M. F. S.; ALMEIDA, L. M. (Org.). Diálogos com a teoria das representações sociais. Recife: Ed. Universitária da UFPE; Ed. Universitária da UFAL, 2005. p. 117-160.

ALMEIDA FILHO, J. C. P. O ensino de línguas no Brasil de 1978. E agora? Revista Brasileira de Linguistica Aplicada, Belo Horizonte, v. 1, n. 1, p. 15-29, 2001. DOI: https://bit.ly/2H8OFwx

BARDIN, L. Análise de conteúdo. Lisboa: Edições 70, 1977.

BATTISTELLA, T.; LIMA, M. S. Feedback corretivo: um estudo sob o espectro interpretativista. Antares, Caxias do Sul, n. 3, p. 180-190, 2010. 
BATTISTELLA, T.; LIMA, M. S. A correção em língua estrangeira a partir de uma perspectiva sociocultural e as crenças de professores sobre o assunto. Revista Brasileira de Linguistica Aplicada, Belo Horizonte, v. 15, n. 1, p. 281-302, 2015. DOI: https://bit.ly/2AFI4nF

BATTISTELLA, T.; LIMA, M. S. O processo de interação em torno do feedback corretivo oral e a teoria sociocultural no ensino de inglês como língua estrangeira. Revista do GELNE, Natal, v. 19, n. 1, p. 52-67, jan.-jun. 2017.

DUARTE, A. B. S. Grupo Focal online e offline como técnica de coleta de dados. Informação \& Sociedade: estudos, João Pessoa, v. 17, n. 1, p. 75-85, abr. 2007. BDOI: 2007-0000268-00007

ELLIS, R. Corrective feedback and teacher development. L2 Journal, California, v. I, p. 3-18, 2009. DOI: 10.5070/12.v1i1.9054

FIGUEIREDO, F. J. Q. de. Aprendendo com os erros: uma perspectiva comunicativa de ensino de línguas. Goiânia: Ed. Da UFG, 2002.

GASKELL, G. Entrevistas individuais e grupais. In: BAUER, M. W.; GASKELL, G. (Org.). Pesquisa qualitativa com texto, imagem e som: um manual prático. 10. ed. Petrópolis: Vozes, 2012. p. 64-89.

GATTI, B. A. Grupo focal na pesquisa em ciências sociais e humanas. Brasília: Liber Livro Editora, 2005.

GOMES, R. Análise e interpretação de dados na pesquisa qualitativa. In: MINAYO, M. C. de S. (Org.). Pesquisa social: teoria, método e criatividade. 21. ed. Petrópolis: Vozes, 2002. p. 67-80.

JODELET, D. Representações Sociais: um domínio em expansão. In: JODELET, D. (Org.). As representações sociais. Rio de Janeiro: EDUERJ, 2001. p. 17-44.

JOVCHELOVITCH, S. Os contextos do saber: representações, comunidade e cultura. Petrópolis: Vozes, 2011.

LEFFA, V. J. Metodologia do ensino de línguas. In: BOHN, H. I.; VANDRESEN, P. Tópicos em Linguística aplicada: o ensino de línguas estrangeiras. Florianópolis: Ed. da UFSC, 1988. p. 211-236.

LIMA, M. S.; PESSÔA, A. R. Conhecimentos e práticas de duas professoras de inglês sobre correção do erro oral. In: FIGUEIREDO, F. J. Q. de; SIMÕES, D. (Org.). Linguística aplicada, prática de ensino e aprendizagem de linguas. Campinas: Pontes Editores, 2016. p. 307-332. 
LYSTER, R; SAITO, K. Oral feedback in classroom SLA: a meta-analysis. Studies in Second Language Acquisition, Cambridge, n. 32, p. 265-302, 2010. DOI: https://bit.ly/2SKA8bA

LYSTER, R; SAITO, K.; SATO, M. Oral corrective feedback in second language classrooms. Language Teaching, Cambridge, v. 46, n. 1, p. 1-40, 2013. DOI: https://bit.ly/2Cell1Z

MORAES, R. Análise de conteúdo. Revista Educação, Porto Alegre, v. 22, n. 37, p. 7-32, 1999.

MOSCOVICI, S. A representação social da psicanálise. Rio de Janeiro: Zahar, 1978.

MOSCOVICI, S. O fenômeno das representações sociais. In: MOSCOVICI, S. (Org.). Representações sociais: investigações em psicologia social. Petrópolis: Vozes, 2003. p. 29-109.

MOSCOVICI, S. Representações sociais: investigações em psicologia social. 5. ed. Petrópolis: Vozes, 2007.

REZABEK, R. Online focus groups: electronic discussions for research. Forum: Qualitative Social Research, Germany, v. 1, n. 1, jan 2000. DOI: http:/ / dx.doi.org/10.17169/fqs-1.1.1128

RUSSEL, V. Corrective feedback over a decade of research since Lyster and Ranta (1997): where do we stand today?. Electronic Journal of Foreign Language Teaching, Singapore, v. 6, n. 1, p. 21-31, 2009.

SÁ, C. P. de. A construção do objeto de pesquisa em representações sociais. Rio de Janeiro: EDUERJ, 1998.

SEVERO, S. S. de. O uso do Whatsapp como ferramenta para o desenvolvimento da habilidade comunicativa em inglês como lingua estrangeira em um contexto de Blended Learning. 2016. $87 \mathrm{f}$. Dissertação (Mestrado em Linguística Aplicada) - Universidade do Vale do Rio dos Sinos, São Leopoldo, 2016.

SHEEN, Y.; ELLIS, R. Corrective feedback in language teaching. Handbook of research in second language teaching and learning. New York; London: Routledge, 2011. p. 593-610.

SWAIN, M. The inseparability of cognition and emotion in second language learning. Language Teaching, [S.1.], v.46, n.2, p. 195-207, 2011. DOI: https://bit. ly/2RHf4FG 


\section{APÊNDICE A - Instrumento de associação livre de palavras}

\section{PERFIL DE RESPONDENTE:}

Gênero: (....) Feminino (....) Masculino

Idade: Estado civil:

Quanto à sua formação, você cursou:

(....) Ensino fundamental em escola pública

(....) Ensino fundamental em escola particular

(....) Ensino médio em escola pública

(....) Ensino médio em escola particular

(....) Nenhum dos anteriores. Por favor, use o verso para explicar.

Você estudou inglês/espanhol em algum curso de língua antes de entrar no curso de Letras? (...) $\operatorname{sim}(\ldots$.$) não$

Se você respondeu afirmativamente, por favor, informe por quantos semestres você estudou: Estudei por ...... semestres.

Você leciona inglês/espanhol? (....) sim (...) não

Se você respondeu afirmativamente, por favor, informe o tipo de local onde você trabalha:

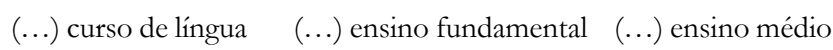

\section{QUESTIONÁRIO PARA COLETA DE DADOS:}

1. Escreva as primeiras 4 palavras que lhe vierem à mente para completar a seguinte frase: "Correção do erro oral na aula de língua estrangeira é..."

2. Qual das palavras que você usou acima é a mais importante?

3. Por que essa é a palavra mais importante?

Você tem interesse e disponibilidade para continuar a participar desta pesquisa de modo virtual? Caso afirmativo, por favor, informe seu e-mail para mantermos contato.

Data de submissão: 17/11/2017. Data de aprovação: 16/11/2018. 